\title{
Etiology, Pathophysiology and Diagnosis of Learning Disability
}

\author{
Rabindran $^{1 *}$, Darshini Madanagopal ${ }^{2}$
}

${ }^{1}$ Consultant, Neonatologist, Billroth Hospital, Chennai, India

${ }^{2}$ Assistant Professor, Department of Psychology, Institute of Distance Education, University of Madras, Chennai, India

DOI: $10.36347 /$ sjams.2020.v08i09.025

| Received: 10.09.2020 | Accepted: 17.09.2020 | Published: 19.09.2020

*Corresponding author: Rabindran

\section{Abstract}

Learning Disability is a type of neurodevelopmental disorder which affects nearly 5\% of school-aged children globally. It affects acquisition, organization, retention, comprehension or use of both verbal and nonverbal information. Children with LD have average or above-average IQ. There are many types of LD. Classification of LD is based on (a) Information processing and (b) By function impairment. LD can be classified into four stages input, integration, storage and output based on information processing. By function impaired there are Dyslexia, Dysgraphia, Dyscalculia, Auditory and Visual Processing Disorder, Nonverbal LD, Dyspraxia and Dysphasia. LD is neurobiological in origin. Both Herditary and environmental factors contribute to its pathophysiology. Some possible risk factors include maternal illness, fetal exposure to alcohol, and use of toxic drugs during pregnancy, complicated pregnancy or delivery and neonatal problems. There are 5 models through which the etiology of LD can be explained namely Difference Model, Deficit Model, Delay Model, Disruption Model and Personal-Historical Model. These models are not mutually exclusive. Neurphysiological and Neuroanatomical studies of brain of dyslexic persons have shown malformations predominantly on the left cerebral cortex. Corticostriatal system disorder is proposed in pathogenesis of LD. Evaluation of a child with LD needs a multidisciplinary approach. Diagnostic evaluation of LD is a sequential process involving Speech and language, cognitive, educational, medical, and psychologic evaluations along with clinical assessment of LD criteria. NIMHANS has developed an index to assess children with LD. Understanding etiology and pathogenesis will help in early identification and early intervention.

Keywords: Learning Disability, NIMHANS Index, Dyslexia.

Copyright @ 2020: This is an open-access article distributed under the terms of the Creative Commons Attribution license which permits unrestricted use, distribution, and reproduction in any medium for non-commercial use (NonCommercial, or CC-BY-NC) provided the original author and source are credited.

\section{INTRODUCTION}

Learning Disability (LD) is a rising problem nowadays. It affects nearly $5 \%$ of school-aged children globally [1]. LD is a type of neurodevelopmental disorder where there is discrepancy between potential and actual levels of academic performance as predicted by the person's intellectual abilities.

\section{Neurodevelopmental disorder}

Neurodevelopmental disorders appear early in childhood before school entry. There is impaired development of social, academic, and/or occupational functioning. These disorders are characterised by dysfunction in attention, memory, perception, language, problem-solving or social interaction. Examples of neurodevelopmental disorder apart from LD include ADHD, ASD and intellectual disability [2].

\section{Learning disability}

Learning disability (LD) is a disorder that affects acquisition, organization, retention, comprehension or use of both verbal and nonverbal information [1]. Children with LD have problems only with learning. They have average or above-average intelligence quotient. Their LD cannot be attributed to emotional disturbance, cultural difference, or disadvantage [3]. DSM-5 has proposed the following symptomatology to diagnose LD [4]. 1) Difficulty in maths, writing, reading, or reasoning skills, 2) Having performance below-average in linguistic tests in writing, reading and mathematics, 3) Presentation during school years, 4) Condition cannot be explained by any neurological, developmental, motor or sensory (hearing or vision) disorder .

\section{Clinical criteria}

Clinical diagnosis of LD is based on DSM-5 criteria. At least one of the following should be present for $\geq 6$ months to diagnose LD 1) Inaccurate and slow reading, 2) Difficulty in comprehension of written 
material, 3) Difficulty spelling words correctly, 4) Difficulty in writing, 5) Difficulty in understanding number sense and 6) Difficulty with mathematical reasoning.

\section{Common types of $\mathrm{LD}$}

There are many types of LD. The classification of LD is based on (a) Information processing and (b) By function impairment.

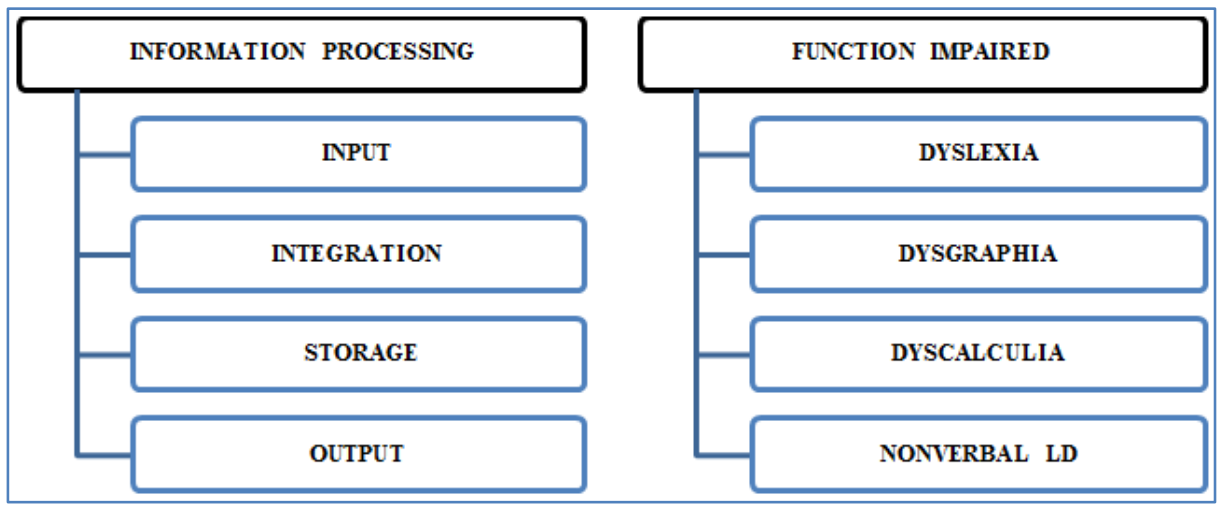

\section{A. BASED ON INFORMATION PROCESSING}

LD can be classified into four stages input, integration, storage and output based on information processing [5]

\section{Input}

There may be defects in visual and auditory processing which could lead to LD. Visual perception defects can lead to difficulty in recognizing shape, position, or size of items seen. Auditory processing defects lead to difficulties to identify competing sounds.

\section{Integration}

Integration is the process of categorizing, sequencing or placing into previous learning. Children with problems in Integration have difficulty in memorizing sequence of information.

\section{Storage}

Storage defects can lead to poor short-term memory or working memory, or long term memory. Due to this defect they have difficulty to learn new material without repetitions. Difficulties with visual memory lead to poor spelling learning.

\section{Output}

Output from the brain occurs through words or motor activity. Language output defects lead to problems with spoken language or written language. Problems with motor activity may cause gross motor or fine motor difficulties.

\section{B. BY FUNCTION IMPAIRED}

The deficit in any area of information processing can manifest in a variety of LD [6].

\section{Dyslexia}

Dyslexia is reading disability. It is the commonest type of LD and constitutes nearly $80 \%$ of all LD. Here there is failure to develop fluent reading in the presence of normal intelligence and environmental support [7]. Pathology is in processing phonemes and holding sounds in sequence in short-term memory. It presents as difficulty with fluent word recognition, word decoding, reading rate and comprehension.

\section{Dysgraphia}

Dysgraphia is writing disorder. It presents with distorted writing, illegible handwriting, mixing upper with lowercase letters, difficulty writing on a line, poor paragraph organization or difficulty holding the pencil [8]. LD with impaired written expression are further subdivided into difficulties with a) spelling accuracy, b) punctuation and grammar accuracy and c) clarity of written expression [4].

\section{Dyscalculia}

Dyscalculia is difficulty in understanding mathematical operations. It presents as difficulty in multiple-step calculations, rearranging numbers (e.g., turning 57 into 75), difficulty in differentiating right from left, poor comprehension of maths concepts, calculation symbols and signs and difficulty memorizing math facts.

\section{Auditory and visual processing disorders}

In this condition there is difficulty understanding language despite normal hearing and vision.

\section{Nonverbal LD}

Nonverbal LD is difficulty in nonverbal functions like problem-solving, visual-spatial tasks and identifying social cues.

\section{Dyspraxia}

Here there are problems with movement and coordination. It may affect fine motor skills or gross motor skills. It is associated with problems in activities demanding hand- eye coordination balance and manual dexterity. 


\section{Dysphasia}

This is language based LD. In this condition, there are problems with verbal language skills. They may present with difficulty in retelling a story, difficulty in fluency of speech and inability to understand the meaning of words and directions [7].

\section{Etiology}

LD is believed to occur due to brain pathology i.e., it is neurobiological in origin. Both Herditary and environmental factors contribute to the pathophysiology of LD [9]. It can be congenital or acquired. Some children have spontaneous mutations leading to increased risk of developing LD [10]. A particular gene mutation at CDK13 gene has been shown to be associated with LD. It has been found that development of LD is more likely in children who have a parent with LD. Similarly LD is more likely among children whose mother who has had less than 12 years of school education. Some possible risk factors include maternal illness, fetal exposure to alcohol, and use of toxic drugs during pregnancy, complicated pregnancy or delivery and neonatal problems [10]. Postnatal factors include environmental toxins, CNS infections, trauma, malnutrition and severe social deprivation [1]. Traumatic brain injury has been associated with later onset of LD

\section{Etiological Models of Learning Disability}

There are 5 models through which the etiology of LD can be explained [11]

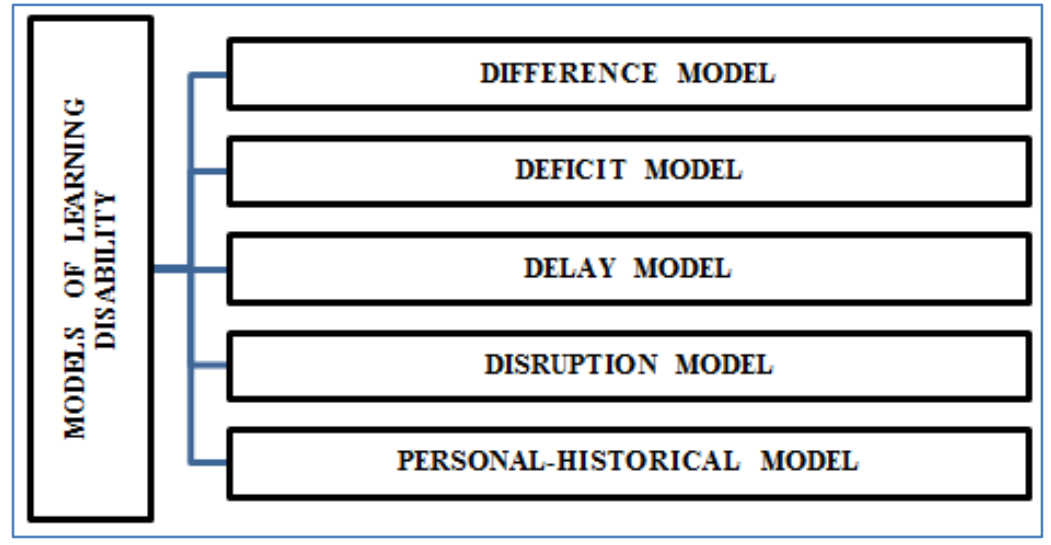

\section{A. The difference model}

Individual differences in cognitive ability are normally distributed in a population. LD occurs due to natural occurrence of poorly developed cognitive skills.

\section{B. The deficit model}

According to this model, LD occurs due to organic conditions like mixed cerebral dominance, brain maldevelopment, and vestibular / ocular difficulties. These deficits interfere with learning.

\section{The delay model}

LD occurs due to immaturity in development .With proper assistance, this would be eventually resolved and academic skills will develop.

\section{The disruption model}

This model states that extraneous factors likes anxiety or depression disrupts the learning process.

\section{E. The Personal-Historical Model}

According to this model, poor development of the basic skills needed for learning occur due to environmental factors like failure in the teaching or learning process.

These 5 models offer different explanations for LD. These models are not mutually exclusive. Etiology of LD per se is multifactorial.

\section{Pathophysiology}

Neurphysiological and Neuroanatomical studies of brain of dyslexic persons have shown malformations predominantly on the left cerebral cortex [12]. Similar to other Neurodevelopmental disorders like obsessive-compulsive disorders, schizophrenia, attention-deficit / hyperactivity disorder and Tourette disorder, disorder of corticostriatal system is proposed in pathogenesis of LD [13].

\section{Diagnostic evaluation}

Evaluation of a child with LD needs a multidisciplinary team approach [14]. The people involved in efficient assessment and management of children with LD include. 


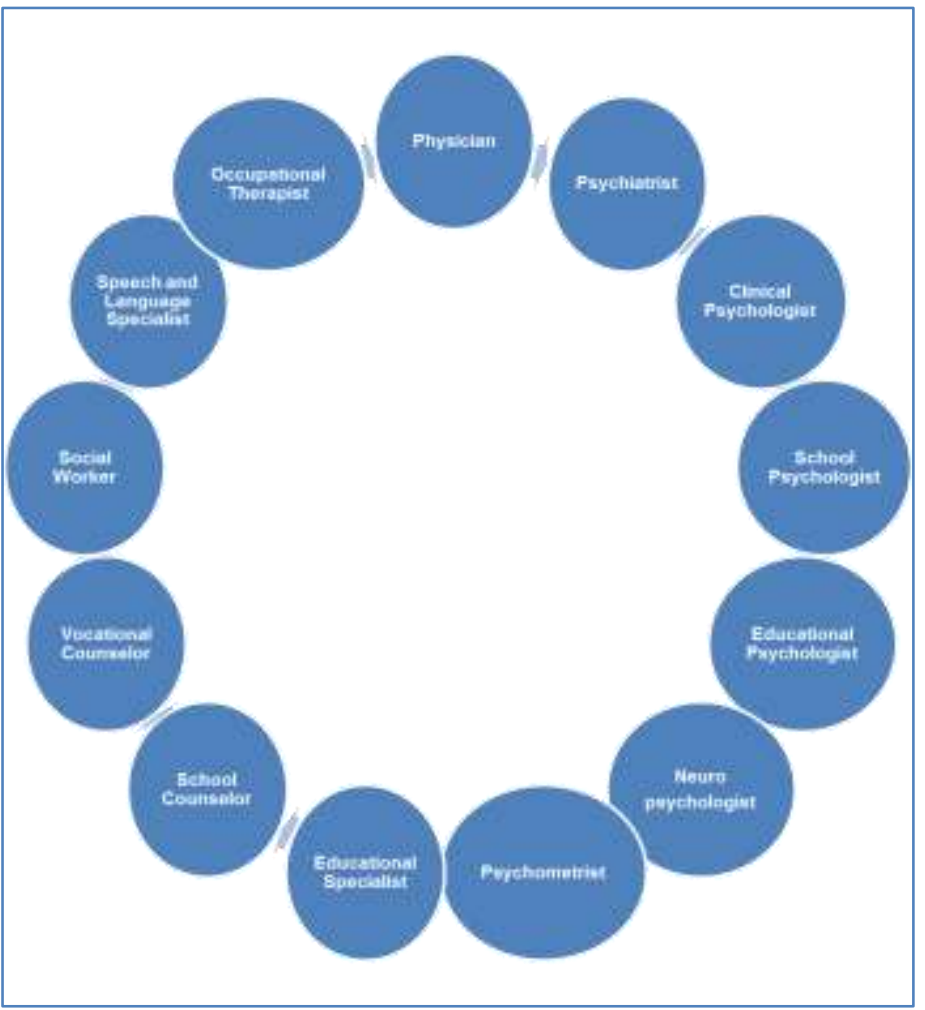

The diagnostic evaluation of $\mathrm{LD}$ is a sequential process involving Speech and language, Cognitive; educational, medical, and psychologic

evaluations along with Clinical assessment of LD criteria.The sequential steps in assessment of LD include the following.

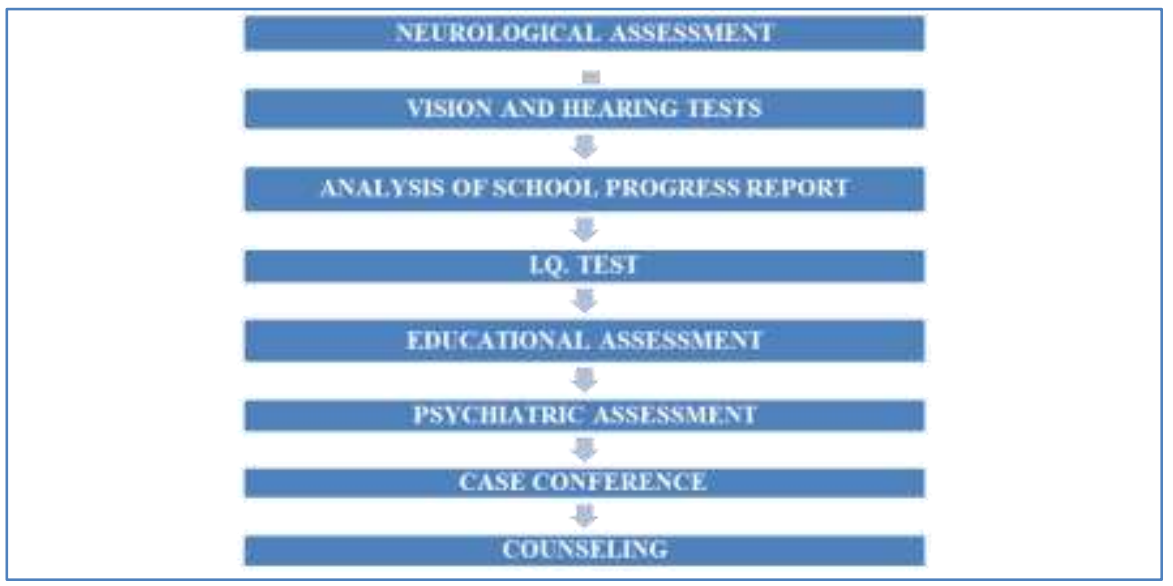

The suspicion of LD arises when there is a discrepancy between academic potential and academic performance. Initially an examination of the child is done with neurological assessment. Hearing and vision tests are then performed to rule out conditions that limit access to guidance and thereby cause LD. A detailed discussion is done with the class teacher regarding the performance of the student and the progress of the child is analysed. IQ assessment is then done by standard IQ assessment tests to identify low intelligence level hindering learning and performance. Speech and language, cognitive, educational evaluations are then done to determine any deficits in skills and cognitive processes. Then Social and emotional-behavioral evaluations are done to plan effective treatment and to monitor progress [15].

Associated developmental or behavioral disorders, like ADHD or autism are then recognized and treatment plan formulated accordingly. Blood, urine, and imaging studies are not routinely done in LD evaluation. Additional investigations are planned when there are neurological findings suggestive of focal brain lesion, skin lesions suggestive of neurocutaneous syndrome and findings suggesting nutritional disorders, genetic diseases or metabolic disorders. Domainspecific academic and cognitive testing is necessary for formal assessment of LD to know the presence and extent. The domains evaluated usually include academic 
achievement, adaptive behaviour, attention and hyperactive disorder, general cognition, general behaviour, language evaluation and visual-motor evaluation. Areas of language processing, attention, memory and nonverbal reasoning are evaluated. Specific academic achievement in core areas, such as mathematics, reading and written expression are also part of LD evaluation [15].

Commonly used tests in the evaluation of suspected LD include

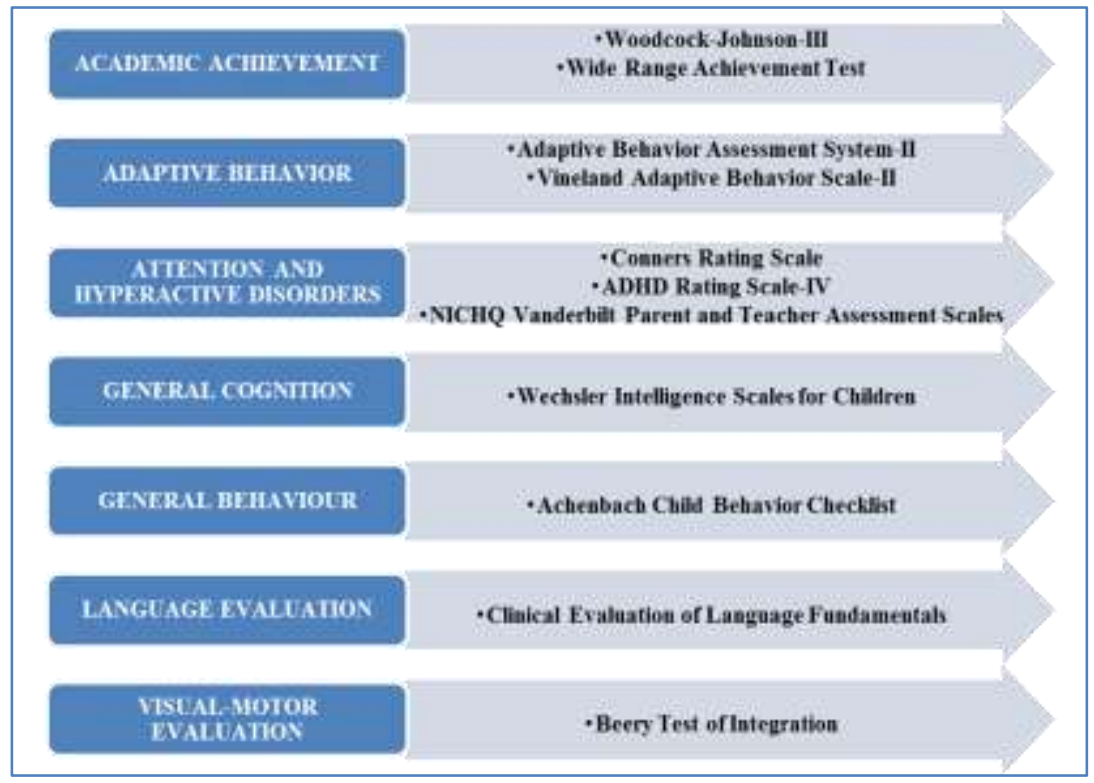

Response to Intervention (RTI) is a novel approach to LD diagnosis. This intervention involves evaluation followed by a restorative instruction in the child's specific area of deficits followed by reassessment. This has the advantage of differentiating LD from lack of instruction [16].

\section{Tests for Evaluation of Learning Disability}

There are various tests commonly used to evaluate LD from preschool through adulthood.

\section{Language: Oral and Written}

1. Assessing Linguistic Behaviors Communicative Intentions Scale (ALB)

2. Clinical Evaluation of Language Fundamentals, $5^{\text {th }}$ Edition (CELF-5)

3. Clinical Evaluation of Language Fundamentals-Preschool, $2^{\text {nd }}$ Edition (CELFPreschool 2)

4. Comprehensive Assessment of Spoken Language (CASL)

5. Developmental Indicators for the Assessment of Learning (DIAL-3)

6. Expressive One-Word Picture Vocabulary Test, $4^{\text {th }}$ Edition (EOWPVT-4)

7. MacArthur Communicative Development Inventories-Words \& Gestures (CDI)

8. Oral \& Written Language Scales: Written Expression (OWLS Written Expression)

9. Peabody Picture Vocabulary Test, $4^{\text {th }}$ Edition (PPVT-4)

10. Preschool Language Scale, $4^{\text {th }}$ Edition (PLS-4)
11. Receptive-Expressive Emergent Language Test, $3^{\text {rd }}$ Edition (REEL-3)

12. Receptive One-Word Picture Vocabulary Test (ROWPVT)

13. Test of Auditory Comprehension of Language, $3^{\text {rd }}$ Edition (TACL-3)

14. Test of Auditory Processing Skills $3^{\text {rd }}$ Edition (TAPS-3)

15. Test of Early Written Language 2 (TEWL-2)

16. Test of Narrative Language (TNL)

17. Test of Pragmatic Language (TOPL)

18. Test of Written Language, $3^{\text {rd }}$ Edition (TOWL-3)

19. Test of Written Spelling, $5^{\text {th }}$ Edition (TWS-5)

20. The Word Test 2: Elementary

21. The Word Test 2: Adolescent

\section{Language and Communication Skills}

1. Apraxia Battery

2. Auditory Skills Battery

3. Brown-Carlson Listening Comprehension

4. Test Clinical Evaluation of Language Functions-Diagnostic Battery

5. Carrol-Sapon Auditory Discrimination Tests

6. Detroit Tests of Learning Aptitude (DTLA)

7. Dictated paragraphs

8. Goldman-Fristoe-Woodcock Test of Auditory Discrimination

9. Illinois Tests of Psycholinguistic Abilities (ITPA)

10. Informal notetaking

11. Informal reading inventory

12. Informal writing inventory 
13. Lindamood Auditory Conceptualization Test

14. Malcomesius Specific Language Disability Test

15. Modern Language Aptitude Test (selected subtests)

16. Morrison-McCall Spelling Scale

17. Peabody Individual Achievement Test (PIAT)

18. Spache Diagnostic Reading Scales

19. Test of Adolescent Language (TOAL)

20. Test of Written Language (TOWL)

21. Wechsler Adult Intelligence Scale-Revised (selected subtests)

22. Wepman Auditory Discrimination Test

23. Wide Range Achievement Test (WRAT) \& WRAT-R

24. Woodcock-Johnson Psycho-Educational Battery

25. Woodcock Reading Mastery Tests

\section{Reading}

1. Comprehensive Test of Phonological Processing, $2^{\text {nd }}$ Edition (CTOPP-2)

2. The Diagnostic Assessments of Reading with Trial Teach Strategies (DAR-TTS)

3. Qualitative Reading Inventory, $5^{\text {th }}$ Edition (QRI-5)

4. Woodcock Reading Mastery Tests-Revised (WRMT-R)

5. Gray Oral Reading Tests, $5^{\text {th }}$ Edition (GORT5)

6. Gray Silent Reading Tests (GSRT)

7. Rapid Automatic Naming \& Rapid Alternating Stimulus Tests

8. The Nelson- Denny Reading Test of Vocabulary, Reading Comprehension,\& Reading Rate

9. Stanford Diagnostic Reading Test (SDRT)

10. Woodcock-Johnson Psycho-Educational Battery (WJPEB)

11. Wide Range Achievement Test 4 (WRAT-R)

12. Woodcock Reading Mastery Test

13. Nelson-Denny Reading Test

14. Informal Reading Assessments

\section{Math Skills}

1. Wide Range Achievement Test (WRAT) / WRAT-A

2. Woodcock-Johnson Psycho-Educational Battery (WJPEB II)

3. Key-Math

4. Stanford Diagnostic Math Test

\section{Achievement}

1. Kaufman Test of Educational Achievement, $2^{\text {nd }}$ Edition Comprehensive Form (KTEA-II)

2. Wechsler Individual Achievement Test, $2^{\text {nd }}$ Edition (WIAT-II)

3. Woodcock Johnson-III Tests of Achievement (WJ III ACH)
Intelligence

1. Kaufman Assessment Battery for Children, $2^{\text {nd }}$ Edition (KABC-II)

2. Stanford-Binet Intelligence Scales for Early Childhood, $5^{\text {th }}$ Edition (Early SB5)

3. Wechsler Preschool and Primary Scale of Intelligence, $3^{\text {rd }}$ Edition (WPPSI-III)

4. Woodcock-Johnson III Tests of Cognitive Abilities (WJ III COG)

5. McCarthy Scales of Children's Abilities (MSCA)

6. Wechsler Intelligence Scale for Children, $4^{\text {th }}$ Edition Integrated (WISC-IV Integrated)

7. Wechsler Adult Intelligence Scale (WAIS-R)

8. RAVENS Progressive Matrices

9. Woodcock-Johnson Psycho-Educational Battery (WJPEB)

10. Peabody Picture Vocabulary Test - Revised (PPVT-R)

11. Test of Nonverbal Intelligence $4^{\text {th }}$ Edition(TONI)

\section{Articulation}

1. Arizona Articulation Proficiency Scale, Third Revision (Arizona-3)

2. Goldman-Fristoe Test of Articulation, Second Edition (GFTA-2)

3. Kaufman Speech Praxis for Children (KSPT)

4. Khan-Lewis Phonological Analysis (KLPA-2)

5. Photo Articulation Test $-3^{\text {rd }}$ Edition (PAT-3)

Social

1. Ages \& Stages Questionnaires: A ParentCompleted, Child-Monitoring System, $2^{\text {nd }}$ Edition (ASQ)

2. Vineland Adaptive Behavior Scales, Second Edition (Vineland-II)

3. Test of Problem Solving 3: Elementary (TOPS-3)

\section{Motor Skills}

1. Bayley Scales of Infant \& Toddler Development- $3^{\text {rd }}$ Edition (Bayley-III)

2. The Beery-Buktenica Developmental Test of Visual-Motor Integration, $5^{\text {th }}$ Edition (Beery VMI)

3. Peabody Developmental Motor Scales, $2^{\text {nd }}$ Edition (PDMS-2)

\section{Visual Perception / Processing}

1. Bender-Gestalt

2. Wechsler Adult Intelligence Scale (WAIS-R) Subtests

3. Woodcock-Johnson Psycho-Educational Battery (WJPEB) Subtests

4. Beery Test of Visual Motor Integration

\section{LD Assessment- Developments in India}

National Institute of Mental Health and Neurosciences (NIMHANS), Bangalore has developed 
an index to assess children with LD. This NIMHANS index has 2 levels. Level I is for children between 5-7 years of age and Level II is for 8-12 years of age. NIMHANS index consists tests for assessment of 1) Attention, 2) Visuo-motor skill, 3) Auditory and Visual Processing, 4) Reading, writing, spelling and comprehension, 5) Speech and Language including Auditory behaviour and Verbal expression and 6) Arithmetic.

\section{Conclusion}

Learning Disability is a modern threat for the future generation. Understanding the etiology and pathogenesis will be helpful in identifying children with LD early. Being a neurodevelopmental disorder, early diagnosis and prompt timely intervention will help the children with LD to adapt to the environment and improve their academic performance.

\section{REFERENCE}

1. Al-Mahrezi A, Al-Futaisi A, Al-Mamari W. Learning disabilities: Opportunities and challenges in Oman. Sultan Qaboos University Medical Journal. 2016 May;16(2):e129.

2. Aud S, Hussar WJ. The condition of education 2012. National Center for Education Statistics; 2012 Nov 29.

3. Lyon GR, Fletcher JM, Barnes MC. Learning disabilities. Future Child. 1996 Spring; 6(1):54

4. McCloskey M, Rapp B. Developmental dysgraphia: An overview and framework for research. Cognitive neuropsychology. 2017 May 19;34(3-4):65-82.

5. Reading and Learning Disabilities". National Dissemination Center for Children with Disabilities (NICHAY). Academy for Educational Development (AED). 2004.

6. Childhood Voyages in Development, Third Edition, Thomson Wadsworth. 2008, 387.

7. Kohli A, Sharma S, Padhy SK. Specific Learning
Disabilities: Issues that Remain Unanswered. Indian J Psychol Med. 2018 Sep-Oct;40(5):399405.

8. Specific Learning Disorder" (PDF). American Psychiatric Association DSM-5 Developmental. American Psychiatric Association; 2013.

9. National Center for Learning Disabilities. Snapshot of learning and attention issues in the U.S. 2017; Retrieved August 7, 2018, from https://www.ncld.org/wpcontent/uploads/2017/03/1-in-5Snapshot.Fin_.03142017.pdf

10. Johnson B. Learning disabilities in children: Epidemiology, risk factors and importance of early intervention. Bmh medical journal-issn 2348-392x. 2017 Jan 1;4(1):31-7.

11. Geetha Gopinath \& Tintu Mathew. Learning disabilities: etiology and types, International Journal of Education \& Applied Sciences Research. 2017;4(1): 15-18

12. Kemper TL. Anatomical basis of learning disabilities. Brain specialization. Otolaryngologic Clinics of North America. 1985 May 1;18(2):30514.

13. Krishnan S, Watkins KE, Bishop DV. Neurobiological basis of language learning difficulties. Trends in cognitive sciences. 2016 Sep 1;20(9):701-14.

14. Reeder DL, Arnold SH, Jeffries LM, McEwen IR. The role of occupational therapists and physical therapists in elementary school system early intervening services and response to intervention: a case report. Physical \& Occupational Therapy in Pediatrics. 2011 Jan 19;31(1):44-57.

15. Fletcher JM, Lyon GR, Fuchs LS, Barnes MA. Learning disabilities: From identification to intervention. Guilford Publications; 2018 Nov 21.

16. Rimrodt SL, Lipkin PH. Learning disabilities and school failure. Pediatrics in Review-Elk Grove. 2011 Aug 1;32(8):315. 